\title{
Pembelajaran Sejarah Berbasis Nilai-Nilai Astha Brata Sebagai Penguatan Sikap Kepemimpinan Siswa SMA
}

\author{
Muhammad Fitri \\ Universitas Sebelas Maret \\ muhammadfitri@student.uns.ac.id
}

\section{Article History}

received $1 / 9 / 2021$

\begin{abstract}
Astha Brata merupakan delapan sifat atau watak (ambeg) delapan dewa yaitu Wisnu (Bumi), Bayu (Angin), Baruna (Samudera), Candra (Bulan), Surya (Matahari), Indra (Langit), Agni (Api) dan Ismaya (Bintang). Dimana terdapat nilai-nilai yang bersifat Adiluhung yang perlu ditanamkan kepada siswa selaku generasi penerus yang akan menjadi pemimpin bangsa ini melalui pembelajaran sejarah. Metode yang digunakan adalah literature Review yang terdiri dari lima tahap meliputi: (1) Mendefinisikan ruang lingkup topik yang akan direview, (2) Mengidentifikasi sumber-sumber yang relevan, (3) Mereview literatur, (4) Menulis review dan (5) Mengaplikasikan literatur pada studi yang akan dilakukan. Penulisan ini bertujuan untuk mendeskripsikan pembelajaran sejarah berbasis nilai-nilai Astha Brata sebagai penguatan sikap kepemimpinan siswa SMA. Hasil literature Review menunjukkan bahwa nilai-nilai Astha Brata penting untuk ditanamkan kepada siswa. Berdasarkan hasil literature Review, dapat disimpulkan bahwa pembelajaran sejarah berbasis nilai-nilai Astha Brata berperan penting sebagai penguatan sikap kepemimpinan siswa SMA.
\end{abstract}

Keywords: Pembelajaran Sejarah, Astha Brata, Penguatan Sikap Kepemimpinan

\begin{abstract}
Abstrak
Astha Brata is an eight nature or character (ambeg) eight gods, namely Vishnu (Earth), Bayu (Wind), Baruna (Ocean), Candra (Moon), Surya (Sun), Indra (Sky), Agni (Fire) and Ismaya ( Star). Where there are values that are Adiluhung that need to be instilled in students as the next generation who will become leaders of this nation through history learning. The method used is a literature review which consists of five stages including: (1) defining the scope of the topic to be reviewed, (2) identifying relevant sources, (3) reviewing the literature, (4) writing a review and (5) applying literature on the study to be carried out. This writing aims to describe learning history based on the values of Astha Brata as strengthening the leadership attitude of high school students. The results of the literature review show that the values of Astha Brata are important to instill in students. Based on the results of the literature review, it can be concluded that learning history based on the values of Astha Brata plays an important role in strengthening the leadership attitudes of high school students.
\end{abstract}

Kata kunci: History Learning, Astha Brata, Strengthening Leadership Attitudes

Social, Humanities, and Education Studies (SHEs): Conference Series https://jurnal.uns.ac.id/shes 


\section{PENDAHULUAN}

Dalam konteks paling sederhana, individu yang berkelompok tentu memerlukan satu Pendidikan merupakan hal yang penting dalam kehidupan berbangsa dan bernegara. Guna melahirkan generasi penerus bangsa yang mampu bersaing dalam segala aspek kehidupan seperti ekonomi, politik, dan sosial. Kenapa harus pemuda, karena merekalah yang akan melanjutkan perjuangan bangsa ini dan menjadi pemeimpin dimasa yang akan datang. Pendidikan berkaitan langsung dengan pembentukan manusia yang merupakan interaksi antara pendidik dan yang terdidik untuk mencapai tujuan pendidikan (Nana Sayodih Sukmadinata, 2012:38).

Tujuan utama pendidikan yaitu untuk mengembangkan kemampuan dan membentuk watak serta peradaban bangsa. Hal ini tidak akan terwujud apabila peserta didik mendapatkan pembelajaran yang tidak tepat sasaran. Untuk itu perlu dilakukan peningkatan kualitas pembelajaran. Peningkatan kualitas pembelajaran harus dilakukan secara terus menerus dan berkesinambungan guna melahirkan generasi emas Indonesia tahun 2045 nanti.

Peningkatan kualitas pembelajaran salah satunya dapat dilakukan dalam pembelajaran sejarah berbasis nilai-nilai Astha Brata yang bertujuan untuk penguatan sikap kepemimpinan kepada siswa yang nantinya akan menjadi pemimpin dimasa yang akan datang. Pembelajaran sejarah tidak lagi menekankan pengajaran fakta hafalan secara afektif doktriner tetapi lebih sarat dengan latihan berfikir historis dan kritis analitis (I Gede Widja,2002:23). Oleh karena itu perlu adanya penanaman nilainilai dari kearifan lokal yang diintegrasikan dalam sebuah pembelajaran sejarah kepada siswa. Hal ini dilakukan agar siswa dapat memahami dan memaknai secara lebih mendalam serta mengimplementasikan nilai-nilai Astha Brata dalam kehidupan sehari-hari sebagai penguatan sikap kepemimpinan.

Salah satu sekolah yang harus mendapatkan penguatan sikap kepemimpinan adalah siswa sekolah menengah atas (SMA). Hal ini karena siswa SMA merupakan usia yang matang sebagai pemuda dan siap untuk menjadi pemimpin bangsa ini. Selain itu, secara umum, visi dan misi dari sekolah menengah atas (SMA) tidak hanya mengedepankan penanaman pengetahuan dan pencapaian prestasi, tetapi juga penguatan sikap yang berkaitan juga dengan karakter siswa. Tujuan dari penelitian ini untuk mendeskripsikan pembelajaran sejarah berbasis nilai-nilai Astha Brata sebagai penguatan sikap kepemimpinan.

Berdasarkan uraian di atas, sangat penting untuk menggali nilai-nilai Astha Brata sebagai penguatan sikap kepemimpinan siswa sekolah menengah atas (SMA). Oleh karena itu, penting untuk dilakukan penelitian berdasarkan literature review tentang Pembelajaran Sejarah Berbasis Nilai-Nilai Astha Brata Sebagai Penguatan Sikap Kepemimpinan Siswa SMA.

\section{METODE}

Berdasarkan kajian yang telah diuraikan di atas, metode yang digunakan dalam penelitian ini yaitu Literatur Review. Literatures review merupakan suatu uraian tentang teoris, temuan dan bahan penelitian lain yang diperoleh dari bahan acuan untuk dijadikan sebagai landasan dalam sebuah kegiatan penelitian. Literature review berisi ulasan, rangkuman, dan pemikiran dari peneliti tentang beberapa sumber pustaka (artikel, buku, slide, informasi dari internet, dll) tentang topik yang dibahas yaitu Pembelajaran Sejarah Berbasis Nilai-Nilai Astha Brata Sebagai Penguatan Sikap Kepemimpinan Siswa SMA.

Literatur review berfokus pada hasil penulisan yang berkaitan dengan topik atau variabel penulisan. Peneliti melakukan literature review setelah menentukan topik penulisan dan ditetapkannya rumusan masalah, sebelum terjun ke lapangan untuk mengumpulan data yang diperlukan (Nursalam, 2016). Literature review yang baik harus bersifat relevan, mutakhir, dan memadai. Landasan teori, tinjauan teori, dan 
tinjauan pustaka merupakan beberapa cara untuk melakukan literature review yang terdiri dari lima tahap meliputi:

(1) Mendefinisikan ruang lingkup topik yang akan direview,

(2) Mengidentifikasi sumber-sumber yang relevan,

(3) Mereview literatur,

(4) Menulis review dan

(5) Mengaplikasikan literatur pada studi yang akan dilakukan.

Literature review tidak hanya bermakna membaca literatur, tapi lebih ke arah evaluasi yang mendalam dan kritis tentang penelitian sebelumnya pada suatu topik. Literature Review is a critical and in depth evaluation of previous research (Shuttleworth, 2009). Literature review yang baik adalah yang melakukan evaluasi terhadap kualitas dan temuan baru dari suatu paper ilmiah. Setelah sumber-sumber terkumpul, Kemudian peneliti review secara kritis dan analitis. Setelah tahap review selesai, kemudian peneliti menulis hasil dari review yang telah dilakukan dan tahap yang terakhir yaitu mengaplikasikan hasil literature review tersebut pada studi yang akan dilakukan.

Pembelajaran Sejarah

\section{HASIL DAN PEMBAHASAN}

Seiring berkembangnya zaman dan dampaknya ke dunia pendidikan, penting untuk memanfaatkan kearifan lokal berbasis Astra Brata dalam pembelajaran, khususnya pembelajaran sejarah. Hal ini dilakukan sebagai salah satu cara untuk menguatkan sikap kepemimpinan kepada siswa dengan cara mengintegrasikan nilainilai Astra Brata dalam pembelajaran. Semenjak dilakukannya pemutakhiran kurikulum dalam pendidikan Indonesia dari Kurikulum Tingkat Satuan Pendidikan (KTSP) menjadi Kurikulum 2013 (K13) sistem penilaian mencakup tiga aspek secara spesifik, yaitu Afektif (Sikap), Kognitif (Pengetahuan), dan Psikomotorik (Keterampilan). Oleh karena itu, berkaitan dengan sikap. Perlu adanya pemanfaatan kearifan lokal nilai-nilai Astha Brata dalam pembelajaran sejarah sebagai penguatan sikap kepemimpinan siswa.

Pembelajaran merupakan jantung dari proses pendidikan. Kualitas pembelajaran bersifat kompleks dan dinamis, dapat dipandang dari berbagai macam persepsi dan sudut pandang yang melintasi garis waktu. Pembelajaran sejarah terdiri dari dua kata, yaitu pembelajaran dan sejarah. Pembelajaran adalah proses atau suatu cara yang dilakukan agar seseorang maupun sekelompok orang dapat melakukan kegiatan belajar untuk membuat diri mereka lebih cepat berkembang. Sedangkan menurut Mulyasa (2006:110), menyebutkan bahwa pembelajaran pada hakikatnya adalah proses interaksi antara peserta didik dan lingkungannya, sehingga terjadi perubahan perilaku kearah yang lebih baik, di mana dalam interaksi tersebut banyak sekali faktor yang mempengaruhinya, baik internal yang ada pada individu, maupun faktor eksternal yang datang dari lingkungan. Pada proses pembelajaran juga tidak hanya lingkungan belajar, tetapi juga meliputi guru, alat peraga, perpustakaan, laboratorium dan sebagainya untuk menunjang proses belajar mengajar di sekolah. Sedangkan pembelajaran sejarah menurut I Gede Widja (1989:23) pembelajaran sejarah adalah aktivitas belajar mengajar, didalamnya memuat pelajaran tentang peristiwa masa lampau yang berkaitan erat dengan masa kini, sebab dengan kacamata masa kini kita mampu mempelajari masa lampau.

Pembelajaran sejarah mempunyai peranan dalam upaya pembentukan karakter bangsa dan menanamkan nilai budaya. Pembelajaran sejarah berfungsi untuk menyadarkan peserta didik akan adanya proses perubahan dan perkembangan 
masyarakat dalam dimensi waktu dan untuk membangun perspektif serta kesadaran sejarah dalam menemukan, memahami, dan menjelaskan jati diri bangsa di masa lalu, masa kini, dan masa depan di tengah-tengah perubahan dunia (Depdiknas, 2003:6). Pembelajaran sejarah juga merupakan cara untuk membentuk sikap sosial. Adapun sikap sosial tersebut antara lain: saling menghormati, menghargai perbedaan, toleransi dan kesediaan untuk hidup berdampingan dalam nuansa multikulturalisme (Susanto, 2014:62). Menurut Fathurrohman (2015:28) menjelaskan bahwa terdapat beberapa komponen dalam kegiatan pembelajaran, salah satunya yaitu tujuan pembelajaran berupa pencapaian hasil kegiatan pembelajaran atau kompetensi yang terdiri dari kognitif, afektif, dan psikomotorik.

Berdasarkan uraian di atas, dapat disimpulkan bahwa pembelajaran sejarah merupakan usaha dari guru agar siswa belajar, yaitu dengan terjadinya perubahan perilaku pada diri pesera didik yang belajar, perubahan itu didapatkannya dalam kemampuan baru yang berlaku dengan waktu yang relatif lama dan karena adanya usaha pembelajaran sejarah merupakan studi yang menjelaskan tentang manusia di masa lampau dengan semua aspek kegiatan manusia seperti politik, hukum, militer, sosial, keagamaan, kreativitas (seperti yang berkaitan dengan seni, musik, arsitektur Islam), keilmuan dan intelektual (Sapriya, 2017:26).

\section{Sasaran dan Tujuan Pembelajaran Sejarah}

Sasaran merupakan sebuah petunjuk untuk mencapai suatu tujuan pembelajaran. Oleh karena itu, dalam setiap pembelajaran sejarah diharapkan memiliki sasaran dan tujuan yang menjadi pokok dalam prosesnya. Sasaran umum pembelajaran sejarah oleh Kochar (2008:7) diuraikan ke dalam beberapa bagian yang dalam hal ini lebih disederhanakan sebagai berikut: a. Menambah pengetahuan tentang kesejarahan. b. Memahami konsep perubahan dan keberlanjutan terkait manusia, ruang dan waktu. c. Melatih kemampuan berfikir kritis dan alanitis serta melatih keterampilan dalam menyelesaikan suatu masalah. d. Menumbuhkan kesadaran berbangsa dan bernegara. e. Menanamkan sikap intelektualitas. Melalui pendapat Kochar di atas, dapat disimpulkan bahwa para peserta didik diharapkan mampu mengembangkan kemampuan berfikir kritis dan rasa ingin tahu yang mendalam mengenai unsur kesejarahan.

Sementara itu Heri Susanto (2014) menagatakan dalam standar isi tujuan pembelajaran sejarah ditetapkan sebagai berikut: 1. Membangun kesadaran peserta didik tentang pentingnya waktu dan tempat yang merupakan sebuah proses dari masa lampau, masa kini, dan masa depan 2. Melatih daya kritis peserta didik untuk memahami fakta sejarah secara benar dengan didasarkan pada pendekatan ilmiah dan metodologi keilmuan 3. Menumbuhkan apresiasi dan penghargaan peserta didik terhadap peninggalan sejarah sebagai bukti peradaban bangsa Indonesia di masa lampau 4. Menumbuhkan pemahaman peserta didik terhadap proses terbentuknya bangsa Indonesia melalui sejarah yang panjang dan masih berproses hingga masa kini dan masa yang akan datang 5. Menumbuhkan kesadaran dalam diri peserta didik sebagai bagian dari bangsa Indonesia yang memiliki rasa bangga dan cinta tanah air yang dapat diimplementasikan dalam berbagai bidang kehidupan baik nasional maupun internasional.

\section{Kepemimpinan}

Pemimpin itu mempunyai sifat, kebiasaan, temperamen, watak dan kepribadian sendiri yang unik dan khas sehingga tingkah laku dan gayanya yang membedakan dirinya dari orang lain. Gaya atau style hidupnya ini pasti akan mewarnai perilaku dan 
tipe kepemimpinannya. Kepemimpinan merupakan kekuatan aspirasional, kekuatan semangat, dan kekuatan moral yang kreatif, yang mampu mempengaruhi para anggota untuk mengubah sikap, sehingga mereka searah dengan kemauan dan aspirasi pemimpin. Padahal semestinya pemimpin merupakan sosok yang menjadi teladan panutan bagi yang dipimpinnya.

Kepemimpinan adalah proses mengarahkan dan mempengaruhi aktivitasaktivitas tugas dari orangorang dalam kelompok. Kepemimpinan berarti melibatkan orang lain, yaitu bawahan atau karyawan yang dipimpin (Sunarto, 2005). Menurut Kartono (2010), pemimpin itu mempunyai sifat, kebiasaan, temperamen, watak dan kepribadian sendiri yang unik khas sehingga tingkah laku dan gayanya yang membedakan dirinya dari orang lain. Sedangkan menurut Winardi (2004) mendefinisikan pemimpin adalah seseorang yang karena kecakapankecakapan pribadinya dengan atau tanpa pengangkatan resmi dapat mempengaruhi kelompok yang dipimpinnya untuk menggerakkan usaha bersama kearah pencapaian sasaransasaran tertentu.

Tugas pokok seorang pemimpin yaitu: 1) Memberikan suatu kerangka pokok yang jelas yang dapat dijadikan pegangan bagi pengikut-pengikutnya; 2) Mengawasi, mengendalikan serta menyalurkan perilaku warga masyarakat yang dipimpinnya; 3) Bertindak sebagai wakil kelompok kepada dunia diluar kelompok yang dipimpin.

\section{Nilai-Nilai Astha Brata}

Secara umum pengertian nilai dipahami sebagai indikator atau tolak ukur bagi manusia sebagai makhluk sosial. Menurut Rokeach dan Bank menyatakan bahwa nilai merupakan suatu tipe kepercayaan yang berada pada suatu lingkup sistem kepercayaan dalam kehidupan bermasyarakat. Oleh karena itu, penting adanya penanaman nilai-nilai kearifan lokal dalam pembelajaran sejarah. Salah satu konsep kepemimpinan berasal dari budaya Indonesia adalah kepemimpinan model Jawa, atau yang lebih dikenal dangan ajaran Asta (Astha) Brata. Secara etimologis kata Asta Brata berasal dari bahasa Sansekerta, Asta berarti delapan; dan Brata: berarti laku atau pedoman (Suyami, 2008). Jika digolongkan kedalam klasifikasi Yukl (2010), ajaran kepemimpinan Asta Brata dapat digolongkan kedalam pendekatan trait yang mengacu pada sifat-sifat apa saja yang harus dimiliki seorang pemimpin.

Kata Asta Brata awalnya berasal dari kitab Manawa Dharma Sastra (kitab hukum Hindu) yang ditulis dalam bahasa Sansekerta. Manawa Dharma Sastra dihimpun oleh Bhagawan Bhirgu yang diajarkan oleh Manu, pemuka agama Hindu. Pada kitab ini disebutkan bahwa seorang raja harus bertindak berlandaskan pada kedelapan sifat dewa (Manu, Pudja, Sudharta, 2003). Asta Brata awalnya tertulis sebagai ajaran agar berperilaku seperti sifat-sifat dewa, itu pun tidak semuanya yang melambangkan elemen alam tertentu. Lebih lanjut, konsep ajaran kepemimpinan Asta Brata pun berkembang dalam berbagai macam variasi. Ajaran Asta Brata salah satunya dipaparkan dalam Serat Rama (Soetomo, Sujata, Astusi, 1993), yang dikisahkan sebagai wejangan Rama kepada Wibisana untuk memimpin kerajaan Ngalengka. Serat Rama merupakan gubahan dari Ramayana Kakawin yang ditulis dalam bahasa Jawa modern oleh Yasadipura I (1729-1803 M) seorang sastrawan Jawa kuno yang berasal dari Kasunanan Surakarta (Ricklefs, 1991). Versi cerita Ramayana lain, salah satunya yang paling populer adalah Ramayana karangan Walmiki. Namun ajaran Asta Brata tidak ditemukan di Ramayana versi Walmiki, ajaran ini hanya ditemukan di Ramayana versi Jawa (Serat Rama).

\section{Gambar 1. 8 Sifat Astha Brata}




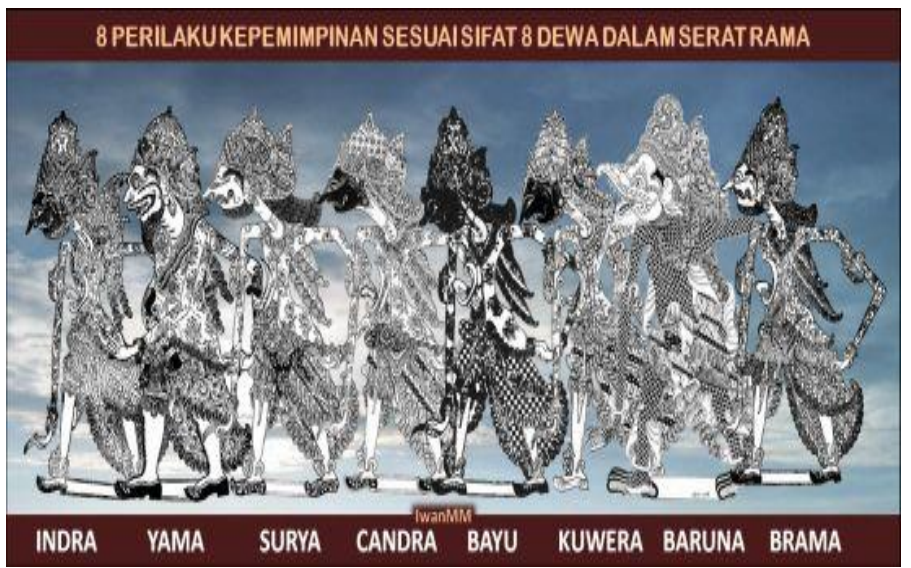

(Sumber: Muljono, 2021)

Berdasarkan gambar 1 di atas, berikut penjelasan terkait Astha Brata. Menurut Moertono ( 1922: 42) terdapat 8 sifat atau watak (ambeg) delapan dewa yaitu Wisnu (Bumi), Bayu (Angin), Baruna (Samudera), Candra (Bulan), Surya (Matahari), Indra (Langit), Agni (Api) dan Ismaya (Bintang).Sifat kebaikan dikaitkan dengan dikaitkan dengan Batara Endra, pemimpin bagi semua dewa. Kemampuan untuk menekan segala kejahatan, dikaitkan dengan dewa bintang Jama. Mempengaruhi dalam kebaikan dan perilaku yang bijak, atribut untuk dewa matahari, Surja. Lovingness atau penuh dengan cinta, dikaitkan dengan batara Tjandra. Kesadaran yang tajam dan wawasan yang mendalam, dikaitkan dengan dewa angin, Baju. Kedermawanan dengan kekayaan materi dan rekreasi dikaitkan dengan dewa laut, Baruna. Keberanian dan tekad yang berapi-api semangat dalam menentang musuh apapun dikaitkan dengan api dewa Brama. Sifat-sifat tersebut harus dimiliki oleh seorang pemimpin dalam memimpin bangsa ini.oleh karena itu, delapan sifat tersebut penting untuk diintegrasikan dalam pembelajaran sejarah kepada siswa sebagai penguatan sikap kepemimpinan mereka.

Sukmadinata (2007) mengemukakan bahwa seiring perkembangan zaman, tantangan yang harus dihadapi konselor adalah pengaruh nilai sosial dan budaya luar, sebab itu memasukkan nilai ajaran Asthabrata untuk mengembangkan karakter kepemimpinan siswa dirasa sangat pantas, hal ini senada dengan pendapat Hurlock (2009) bahwa budya memiliki peran dalam mengembangkan karakter individu. Hal tersebut juga diperkuat dengan pendapat Tilaar (2004) bahwa internalisasi nilai budaya daapt menjadi alternatif penguat karakter bangsa.Berdasarkan hasil literature review yang dilakukan dari sumber jurnal. Diketahui bahwa penting untuk mengintegrasikan sebuah kearifan lokal dalam pembelajaran sejarah sebagai penguatan sikap kepemimpinan siswa. Salah satunya yaitu Astha Brata. Hasil penelitian yang peneliti review secara kritis dan analitis disajikan pada tabel berikut.

Tabel 1. Hasil Penelitian yang direview

\begin{tabular}{llll}
\hline No. & \multicolumn{1}{c}{ Judul } & \multicolumn{2}{c}{ Penulis } \\
\hline 1. & Implementasi Pembelajaran Sejarah Berbasis & Yessi Diana Saputri, \\
& Kearifan Lokal Kepemimpinan Asta Brata Untuk & Sariyatun, \\
& Meningkatkan Karakter Siswa (Studi Kasus di Kelas & Yunianto \\
& X MIA 7 SMAN 3 Surakarta) & & \\
2. & Studi Eksplorasi & Konstrak Kepemimpinan Model & Moh. As'ad, Wahyu \\
\hline
\end{tabular}




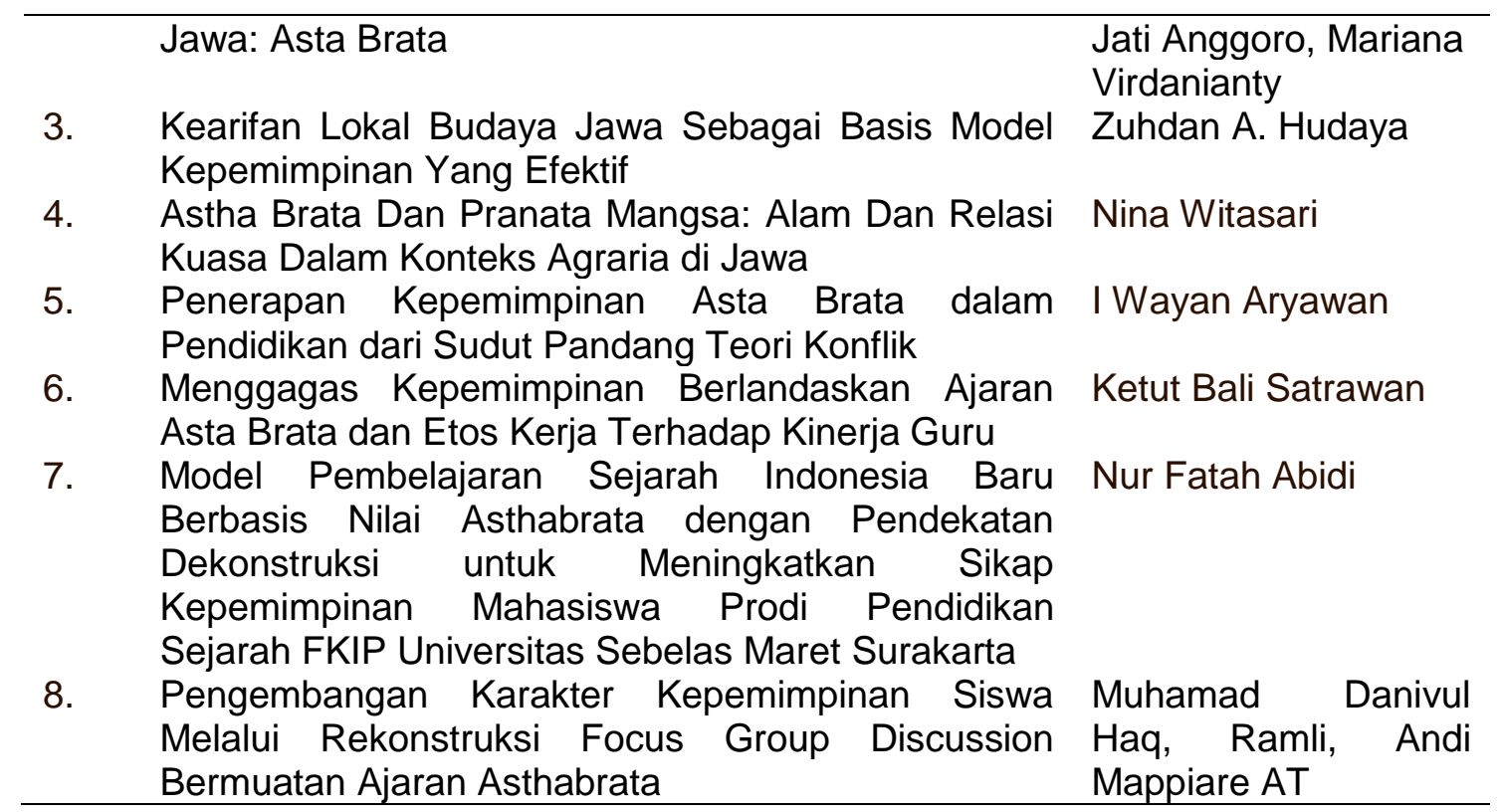

(Sumber: pribadi, 2021)

Berdasarkan tabel 1 di atas, diketahui bahwa peneliti menggunakan 8 sumber untuk melakukan literature review dalam penelitian ini. Dari hasil literature review yang telah dilakukan, diketahui bahwa nilai-nilai Astha Brata sangat penting untuk diintegrasikan dalam pembelajaran sejarah di Indonesia sebagai penguat sikap kepemimpinan siswa SMA. Oleh karena itu, diharapkan kedepannya guru mampu untuk memanfaatkan Astha Brata dalam pembelajaran sejarah. Hal tersebut dilakukan untuk membentuk kepemimpinan siswa. Kenapa harus siswa? Karena mereka adalah generasi muda yang kedepannya akan menjadi pemimpin bangsa.

Hal tersebut senada dengan penelitian yang dilakukan oleh Saputri, dkk dengan jurnalnya yang berjudul Implementasi Pembelajaran Sejarah Berbasis Kearifan Lokal Kepemimpinan Asta Brata Untuk Meningkatkan Karakter Siswa (Studi Kasus di Kelas $X$ MIA 7 SMAN 3 Surakarta). Pembelajaran sejarah yang dilakukan dengan berbasis kearifan lokal Astha Brata dapat memperkuat sikap kepemimpinan siswa SMA. Meskipun secara keseluruhan penelitian yang dilakukan oleh Saputri, dkk tidak sama persis. Jika penelitian yang dilkukan oleh Saputri,dkk untuk meningkatkan karakter siswa. Sedangkan penelitian ini dilakukan sebagai penguat sikap kepemimpinansiswa melalui nilai-nilai Astha Brata. Akan tertapi, memiliki persamaan yaitu sama-sama meneliti tentang pembelajaran sejarah dengan mengintegrasikan Astha Brata dalam proses belajar mengajarnya. Dalam penelitian ini penulis menggunakan pendekatan nilai-nilai kearifan lokal asta brata yang terdapat dalam pewayangan Ramayana dan banyak ditemukan di berbagai candi-candi peninggalan kerajaan Hindu Buddha. Asta brata memuat delapan nilai karakter yang didasarkan pada sifat alam untuk memperkuat karakter kepemimpinan. Ditinjau dari hasil penelitian bahwa penggunaan nilai kearifan lokal astha brata pada pembelajaran sejarah berdampak dalam proses pembelajaran dan penguatan sikap kepemimpinan siswa SMA.

Sejalan dengan penelitian yang dilakukan oleh Nur Fatah Abidi yang berjudul Model Pembelajaran Sejarah Indonesia Baru Berbasis Nilai Asthabrata dengan Pendekatan Dekonstruksi untuk Meningkatkan Sikap Kepemimpinan Mahasiswa Prodi Pendidikan Sejarah FKIP Universitas Sebelas Maret Surakarta. Sejalan dengan 
penelitian tersebut, penelitian yang dilakukan ini sama-sama mengangkat atau mengintegrasikan nilai dari Astha Brata dalam sebuah pembelajaran. Hal tersebut tentunya membuktikan bahwa delapan sifat yang ada dalam Astha Bratha sangat penting untuk diintegrasikan dalam pembelajaran. Baik itu untuk siswa SMA ataupun untuk mahasiswa di perguruan tinggi.

Selain itu, penelitian yang dilakukan oleh Moh. As'ad, dkk dengan judul Studi Eksplorasi Konstrak Kepemimpinan Model Jawa: Asta Brata juga mengatakan bahwa delapan sifat yang ada dalam Astha Brata harus dimiliki oleh seorang pemimpin. Oleh karena itu, penting untuk diajarkan sekarang kepada siswa SMA agar pada saat mereka menjadi pemimpin bangsa ini mereka telah memiliki bekal awal tentang delapan sifat dalam budaya Jawa yaitu Astha Brata. Asta Brata mengungkapkan bahwa salah satu isu sentral dalam dunia psikologi adalah banyaknya penelitianpenelitian tipikal psikologi yang cenderung mengarah pada fondasi, ide dan instrumentasi dari dunia barat. Sedangkan penelitian di barat memiliki batasan budaya (culture bound). Hasil penelitian Moh. As'ad sejalan dengan hasil penelitian ini terkait Astha Brata. berdasarkan hasil penelitian Pembelajaran Sejarah berbasis kearifan lokal asta brata, bahwa dengan menggunakan nilai-nilai kearifan lokal kepemimpinan asta brata dapat digunakan sebagai penguatan sikap kepemimpinan.

Hal ini sejalan dengan hasil penelitian Zuhdan A. Hudaya dalam penelitiannya yang berjudul Kearifan Lokal Budaya Jawa Sebagai Basis Model Kepemimpinan Yang Efektif yang menyatakan bahwa kearifan lokal budaya Jawa tentang kepemimpinan asta brata memberikan pandangan baru terhadap pembelajaran sejarah. Zuhdan mengatakan bahwa penting adanya penanaman budaya Jawa berbasis kepemimpinan kepada generasi muda yang dianggap efektif dimasa yang suda semakin maju seperti sekarang ini. Sejalan dengan penelitian ini, konsep yang digunakan dalam penelitian adalah sama. Maksudnya sama-sama untuk mengintegrasikan kearifan lokal budaya Jawa Astha Brata dalam membentuk seorang pemimpin.

Selain itu, penelitian yang dilakukan oleh Muhamad Danivul Haq, dkk dengan judul Pengembangan Karakter Kepemimpinan Siswa Melalui Rekonstruksi Focus Group Discussion Bermuatan Ajaran Asthabrata. Secara tegas mengatakan bahwa salah satu cara dalam membentuk seorang pemimpin yang baik kepada siswa dimasa sekarang ini guna menatap masa depan adalah dengan cara memasukan nilai-nilai Astha Brata dalam pembelajaran.

Sejalan dengan hal tersebut, penelitian yang dilakukan oleh Nina Witasari yang berjudul Astha Brata Dan Pranata Mangsa: Alam Dan Relasi Kuasa Dalam Konteks Agraria di Jawa. Penelitian yang dilakukan oleh I Wayan Aryawan dengan judul Penerapan Kepemimpinan Asta Brata dalam Pendidikan dari Sudut Pandang Teori Konflik. Penelitian yang dilakukan oleh Ketut Bali Satrawan dengan judul Menggagas Kepemimpinan Berlandaskan Ajaran Asta Brata dan Etos Kerja Terhadap Kinerja Guru. Dari ketiga hasil penelitian tersebut. Dapat diketahui bahwa penelitian ini sejalan dengan ketiganya, karena sama-sama membahas tentang kepemimpinan dalam budaya Jawa yaitu Astha Brata.

Berdasarkan hasil penelitian dengan metode literature review di atas, diketahui bahwa nilai-nilai yang terkandung dalam delapan sifat kepemimpinan Astha Brata sangat penting untuk diintegrasikan kedalam pembelajaran sejara kepada siswa SMA. Karena merekalah yang akan menjadi pemimpin bangsa ini kedepannya. 


\section{SIMPULAN}

Berdasarkan hasil literature review yang dilakukan secara kritis dan analitis yang penelitia lakukan, maka dapat ditarik kesimpulan bahwa:

1. Penerapan pembelajaran sejarah berbasis Astha Brata penting dilakukan dalam pembelajaran sejarah sebagai penguat sikap kepemimpinan siswa SMA. Kenapa harus SMA? Karena siswa SMA termasuk dalam usia yang matang untuk menerima pembelajaran seperti itu.

2. Penerapan pembelajaran sejarah berbasis Astha Brata dapat menjadi penguat sikap kepemimpinan siswa. Hal tersebut terbukti dari berbagai hasil penelitian yang direview. Harapan peneliti untuk kedepannya, semoga penelitian tentang Astha Brata lebih diperdalam lagi. Karena Astha Brata sangat diperlukan bagi seorang pemimpin bangsa ini.

\section{DAFTAR PUSTAKA}

Depdiknas. (2003). Kurikulum 2004. Pedoman Khusus Pengembangan Silabus dan Penilaian Mata Pelajaran Sejarah. Jakarta. Ensiklopedi Nasional Indonesia Jilid 6. 1989. Jakarta: Cipta Adi Pustaka.

Fathurrohman, Muhammad. (2015). Paradima Pembelajaran Kurikulum 2013: Strategi Alternatif Pembelajaran di Era Global. Yogyakarta: Kalimedia.

I Gde Widja. (1989). Sejarah Lokal Suatu Perspektif Dalam Pengajaran Sejarah. Jakarta: Departemen Pendidikan dan Kebudayaan.

I Gede Widja. (2002). Sejarah Lokal Suatu Perspektif Dalam Pengajaran Sejarah. Jakarta : Proyek Pengembangan Lembaga Pendidikan Tenaga Kependidikan.

Kartono Kartini Dr. (2010). Pemimpin dan Kepemimpinan. Jakarta: PT. Raja Grafindo Perkasa.

Kochhar, S.K. (2008). Teaching of History, terjemahan oleh Purwanta dan Yovita Hardiwati. Jakarta: Gramedia Widiasarana Indonesia.

Manu. \& Sudharta, Tjokorda Rai. \& Pudja, Gede. (2003). Manawa dharmasastra, Manu dharmasastra, atau, Weda smrti:

Nana Sayodih Sukmadinata. (2012). Metode Penelitian Pendidikan. Jakarta : Rosda

Mulyasa E. (2006). Menjadi Kepala Sekolah profesional, Bandung, Remaja Rosdakarya.

Ricklefs, M. (1991). Sejarah indonesia modern (terj.). Yogyakarta: Gadjah Mada University Press

Sapriya. (2017). Pendidikan IPS Konsep dan Pembelajaran. Bandung: PT Remaja Rosdakarya.

Soetomo, Sujata, P. Astusi, S. (1993). Serat Rama. Semarang: Yayasan Studi Bahasa Jawa Kanthil

Sunarto. (2005). Manajemen Sumber Daya Manusia. Yogyakarta: Amus

Susanto, Heri. (2014). Seputar Pembelajaran Sejarah: Isu, Gagasan dan Strategi dalam Pembelajaran. Yogyakarta: Aswaja Pressindo.

Suyami (2008). Konsep kepemimpinan jawa dalam ajaran sastra cetha dan astha brata. Yogyakarta: Kepel Press.

Winardi, J. (2004). Motivasi dan Pemotivasian dalam Manajemen. Raja Grafindo perkasa: Jakarta.

Yukl, G. (2010). Leadership in organization: 7th edition. New Jersey: PearsonPrenctice Hall. 